\title{
Governança ambiental na revitalização dos riachos urbanos na Cidade do Recife -
}

\section{Pernambuco - Brasil}

\author{
Environmental governance in the revitalization of urban streams in Recife - Pernambuco - Brazil \\ Gobernanza ambiental en la revitalización de alcance urbanos en la Ciudad de Recife -
}

Pernambuco - Brasil

Recebido: 03/09/2021 | Revisado: 10/09/2021 | Aceito: 14/09/2021 | Publicado: 16/09/2021

\author{
Renata Laranjeiras Gouveia \\ ORCID: https://orcid.org/0000-0002-3691-0060 \\ Instituto Avançado de Tecnologia e Inovação, Brasil \\ E-mail: renatalaranjeiras@gmail.com \\ Vanice Santiago Fragoso Selva \\ ORCID: https://orcid.org/0000-0002-2477-3898 \\ Universidade Federal de Pernambuco, Brasil \\ E-mail: Vanice.ufpe@gmail.com
}

\begin{abstract}
Resumo
A falta de planejamento das cidades no Brasil fez com que a expansão urbana ocorresse de forma desordenada, habitando as margens de rios e riachos. Pelo saneamento precário, os esgotos acabam por serem lançados in natura dentro dos corpos hídricos, como também resíduos sólidos vão parar em seu interior. A canalização dos riachos é observada na cidade do Recife, que possui 98 riachos que escoam para sete bacias e sub-bacias de concentração. Esta pesquisa objetivou analisar o processo de governança ambiental na revitalização dos riachos urbanos na cidade do Recife, em Pernambuco. Realizou-se uma pesquisa de abordagem qualitativa, com entrevistas com os stakeholders. Os líderes das comunidades informam que os canais de comunicação com os órgãos das Prefeituras não são eficientes e que eles só sabem das obras nas suas comunidades no início delas, sem participarem das tomadas de decisão. Isto reflete a governança ambiental no processo de revitalização. Neste processo, há indícios da utilização dos princípios da governança, como: transparência, subsidiariedade, pertencimento e responsabilização. Notou-se maior dificuldade e incipiência nos princípios da descentralização, flexibilidade, participação e segurança.
\end{abstract}

Palavras-chave: Governança; Revitalização; Riachos; Participação.

\begin{abstract}
The lack of planning of cities in Brazil caused urban sprawl to occur in a disorderly manner, inhabiting the banks of rivers and streams. Due to poor sanitation, the sewage ends up being released in natura into the water bodies, as well as solid waste will stop inside. The channeling of the streams is observed in the city of Recife, wich has 98 strems that flow to seven concentration basins and sub-basins. This research aimed to analyze the process of environmental governance in the revitalization of urban streams in the city of Recife in Pernambuco. A qualitative research was conducted, with interviews with stakeholders. Community leaders report that the channels of communication with the municipal authorities are not efficient and that they only know about the works in their communities at the beginning of them, without participating in decision making. This reflects environmental governance in the revitalization process. In this process, there are indications of the use of governance principles, such as: transparency, subsidiatity, belonging and accountability. There was greater difficulty and incipience in the principles of decentralization, flexibility, participation and security.
\end{abstract}

Keywords: Governance; Revitalization; Streams; Participation.

\section{Resumen}

La falta de planificación en las ciudades de Brasil hizo que la expansión urbana se desarrollara de manera desordenada, habitando las riberas de ríos y arroyos. Debido al mal saneamiento, las aguas residuales terminan siendo vertidas in natura a los cuerpos de agua, así como los residuos sólidos terminan en el interior. La canalización de arroyos se observa en la ciudad de Recife, que cuenta con 98 arroyos que desembocan en siete cuencas y subcuencas de concentración. Esta investigación tuvo como objetivo analizar el proceso de gobernanza ambiental en la revitalización de los arroyos urbanos en la ciudad de Recife, Pernambuco. Se realizó una investigación de enfoque cualitativo, con entrevistas a las partes interesadas. Los líderes comunitarios informan que los canales de comunicación con los órganos del Ayuntamiento no son eficientes y que solo conocen las obras en sus comunidades al inicio de las mismas, sin participar en la toma de decisiones. Esto refleja la gobernanza ambiental en el proceso de revitalización. En este proceso, se evidencia el uso de principios de gobernanza, tales como: transparencia, 
subsidiariedad, pertenencia y rendición de cuentas. Se observó mayor dificultad e incipiencia en los principios de descentralización, flexibilidad, participación y seguridad.

Palabras clave: Gobernanza; Revitalización; Corrientes; Participación.

\section{Introdução}

O crescimento urbano mundial ocorreu em um primeiro momento, com a Revolução Industrial, no final do século XVIII, tendo se intensificado posteriormente à II Guerra Mundial. Com isso, viu-se a necessidade por moradias e habitações para abrigar as pessoas oriundas da zona rural para morar nas cidades em busca de melhores condições de vida. Esse quadro é observado no Brasil a partir do processo de industrialização, iniciado na década de 1950, que atraiu para as grandes cidades pessoas do campo e de pequenas cidades (Bonini, 2008) em busca de trabalho, o que provocou a expansão de áreas ocupadas nas cidades incluindo-se margens de rios e riachos.

De acordo com Oliveira e Gomes (2021) é entre os anos de 1960 e 1980 que grande parte da população brasileira passa a habitar o espaço tido como urbano. Constituído pela separação entre as regiões mais valorizadas sendo bem opostas as periferias, cortiços, vilas, mocambos e as favelas. Como destaca Vargas (2008), a falta de planejamento das políticas públicas e a ausência de uma estrutura administrativa que seja eficaz na fiscalização são fatores que permitem esta ocupação irregular. Estas pessoas, por estarem desprovidas de serviço de coleta de lixo e esgotamento sanitário utilizam o corpo d'água para esta função, o que acaba resultando em uma baixa valorização do recurso natural, favorecendo seu uso como um canal natural de esgoto e um depósito de resíduos.

Com isso, os riachos urbanos foram canalizados e retificados com o intuito de melhoria na drenagem da cidade, e também para evitar a proliferação de algumas doenças. Como destaca Carvalho (2012), esta forma de pensamento apenas acabou transferindo o problema para outro local. A longo prazo, a canalização ocasionou consequências para o ambiente, como: perda de biodiversidade, falta de alimentação dos aquíferos, alteração do ciclo hidrológico, degradação da qualidade da água, diminuição da qualidade de vida das pessoas. O processo de crescimento da cidade do Recife (PE) se deu de forma desordenada e a falta de planejamento trouxe consigo graves alterações para o ecossistema urbano, principalmente em relação a drenagem. Considerando o sítio urbano da cidade do Recife um ambiente estuarino, com manguezais e terras baixas foi necessário a abertura de canais de drenagem para atender a lógica do desenvolvimento das cidades.

Os riachos urbanos da cidade foram canalizados e retificados, este fator se agrava quando se tem uma cidade localizada em uma planície costeira, com altas pluviosidades e suscetível às oscilações das marés. Para Guedes, Araújo \& Andrade $(2021$, p.) "a falta da gestão e planejamento dos recursos hídricos afeta diretamente os rios, os lagos, os córregos e mananciais. A baixa infiltração leva a mudança nos níveis do lençol freático, atingindo os aquíferos, que são abastecidos pela infiltração das águas superficiais pelo solo". Busca-se agora reverter o quadro de degradação dos riachos e com isso surgem os projetos de revitalização, renaturalização e requalificação. Projetos de revitalização já são vistos com sucesso em diversas partes do mundo, na busca de uma gestão ambiental adequada de áreas urbanas e da inserção de cidades em espaços competitivos, a revitalização de rios aparece nas agendas de gestão pública de grandes e médias cidades nos últimos 50 anos culminando com a despoluição dos rios Tâmisa (Inglaterra), Sena (Paris), Danúbio e a readequação de rios como o Don (Canadá), Los Angeles e Anacostia (Estados Unidos).

Porém, só há efetivação e continuidade pelo zelar dos riachos, se houver governança na gestão deles. A governança ambiental surge como um forte aliado para o alcance da sustentabilidade ambiental, e é ela que vai direcionar para práticas efetivas de revitalização dos riachos urbanos, pois é a partir da entrada de novos atores nos processos decisórios que as obras podem ocorrer de forma a garantir que sejam eficazes e que se perpetuem dentro da cidade, podendo, por fim, alcançar um desenvolvimento sustentável. Sendo assim, a governança ambiental se conceitua como o relacionamento das ações entre os variados atores, podendo ser humanos ou não, que elaboram contexturas sociais, econômicas e políticas (Matarazzo, Quintão 
\& Serva, 2021). Também envolve a cooperação de diferentes formas, como a parceria, atuando para a transformação política, social, econômica e ambiental para projetos que visam o desenvolvimento sustentável (Espada, Sobrinho, 2015). Com base no exposto, esta pesquisa tem como hipótese que a estrutura de governança existente na cidade do Recife (PE) para a revitalização/renaturalização dos riachos urbanos atua para a minimização dos problemas da macrodrenagem da cidade. Diante da hipótese explicitada, o objetivo geral desta pesquisa constituiu em analisar como se dá o processo de governança ambiental na revitalização dos riachos urbanos na cidade do Recife, Pernambuco, Brasil.

\section{Metodologia}

A seguir são elencados o locus onde se desenvolveu a pesquisa, assim como os métodos utilizados para a coleta e análise dos dados apresentados.

\subsection{Locus da Pesquisa}

Foi utilizada como referência para se testar a hipótese, a cidade do Recife (PE) (Figura 1), cidade cortada por diversos rios e riachos que compõem sua malha hídrica, porém grande parte dos seus riachos urbanos foram canalizados e retificados ao longo do tempo.

A cidade possui 98 canais (riachos urbanos), de acordo com o Cadastro de Canais (2016), realizado pela Empresa de Manutenção e Limpeza Urbana da Cidade do Recife (EMLURB) que escoam para bacias e sub-bacias de concentração formada pelos seguintes rios: Capibaribe, Jordão, Tejipió, Jiquiá, Beberibe, Moxotó, Morno, Camaragibe e Jaboatão, distribuídas pelos bairros de consolidação mais antiga: norte, centro e sul da área urbana.

Figura 1 - Localização da área de estudo: Recife, Pernambuco, Nordeste do Brasil.

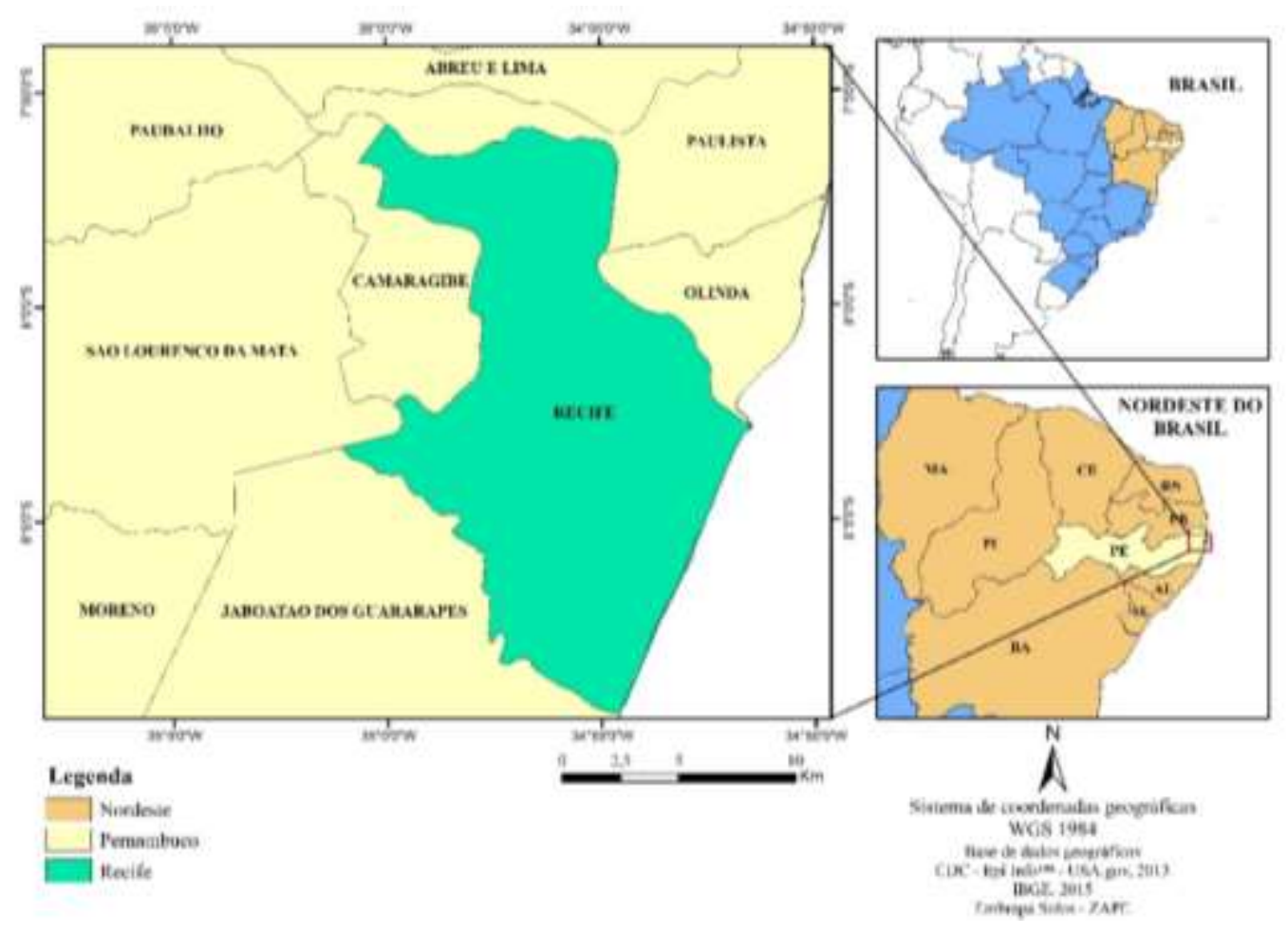

Fonte: SIG/IBGE (2015). 


\subsection{Coleta e análise dos dados}

Foi realizada uma pesquisa qualitativa, onde optou-se por entrevistas estruturadas com indivíduos sociais com uma vinculação pertinente ao problema investigado, sendo dos seguintes segmentos: poder público, empresa privada, universidade e líderes comunitários; objetivando identificar quem são os coordenadores/colaboradores/articuladores na governança ambiental acerca da revitalização/renaturalização dos riachos urbanos na cidade do Recife. Esta pesquisa foi validada pelo Comitê de Ética em Pesquisa da Universidade Federal de Pernambuco, através do parecer 2.418.997.

Foram definidos os seguintes atores para a realização das entrevistas de acordo com o seu papel de interesse (stakeholders):

- Gestores da Empresa de Urbanização do Recife (URB), incluída na Secretaria de Planejamento Participativo, Obras e Desenvolvimento Urbano e Ambiental: limpeza e manutenção dos riachos;

- Gestores da Empresa de Manutenção e Limpeza Urbana do Recife (EMLURB), incluída na Secretaria de Infraestrutura e Serviços Urbanos: execução das obras nas áreas de riachos.

- Secretaria de Desenvolvimento Sustentável e Meio Ambiente do Recife; relacionadas com as questões ambientais e de propostas de Renaturalização para riachos.

- Câmara técnica de Saneamento (Conselho das Cidades): discussão para a tomada de decisão, não é um órgão deliberativo.

- Grupo de Recursos Hídricos da Universidade Federal de Pernambuco: discussões, apontando soluções e mobilizando grupos internos para garantir a revitalização.

- Gestores da Agência Estadual de Meio Ambiente (CPRH): responsáveis pela gestão das bacias;

- Empresa privada: ABF Engenharia, serviços e comércio LTDA: atuam nas discussões para a revitalização. Formularam o Plano de Drenagem do Recife.

- Líderes comunitários do entorno dos riachos urbanos do Recife: Parnamirim, Serpro, ABC, Caiara, Santa Rosa, São Mateus e Valença: interesses da comunidade, como melhoria da qualidade da vida.

A entrevista estruturada foi selecionada como técnica, pois "é um procedimento utilizado na investigação social, para a coleta de dados ou para ajudar no diagnóstico ou no tratamento de um problema social (Marconi \& Lakatos, 2007, p.197), apresentando seis tipos de objetivos: averiguação de fatos; determinação das opiniões sobre os fatos; determinação de sentimentos; descoberta de planos de ação; conduta atual ou do passado; e, motivos conscientes para opiniões, sentimentos, sistemas ou condutas, assim como também corrobora Pereira (2018).

Ela é estruturada no sentido de que o entrevistador segue um plano previamente estabelecido de acordo com um formulário e realizada com pessoas que foram anteriormente selecionadas (Marconi \& Lakatos, 2007).

$\mathrm{O}$ roteiro da entrevista permeou acerca dos princípios de boas práticas da governança, destacados por Bursztyn e Bursztyn (2012) (descentralização, subsidiariedade, flexibilidade, decisões bottow-up, participação/empoderamento, pertencimento, responsabilização, transparência e segurança) para a compreensão de como os riachos urbanos são percebidos e o tratamento que eles recebem pelos gestores públicos, empresa privada e líderes comunitários. Para se obter uma maior representação de grupos sociais que estejam de alguma forma envolvidos com os riachos urbanos, foram entrevistadas 12 pessoas.

Desta forma, para se manter o anonimato dos entrevistados, conforme compromisso assinado através de um Termo de Consentimento Livre e Esclarecido (TCLE), foram identificados com os códigos relacionados, contendo as seguintes legendas: EPP (Entrevistado poder público); EEP (Entrevistado empresa privada); EU (Entrevistado Universidade); e, ESC (Entrevistado Sociedade Civil). 
Para análise dos dados foi utilizado o software para estudos acadêmicos NVivo Pro. De acordo com Lage (2011, p.200), "estas ferramentas computacionais tendem a ser especialmente úteis, quando se tem uma pesquisa qualitativa com grande volume de dados ou quando é necessário cruzar informações a partir dos atributos dos sujeitos de pesquisa".

Sendo assim, as entrevistas foram separadas de acordo com o princípio da governança a qual se referia, onde foram designados como "códigos". O software foi essencial na análise das falas dos entrevistados, pois foi possível um melhor agrupamento dos resultados, o que permitiu uma análise sobre a governança.

\section{Resultados e Discussão}

A gestão dos corpos hídricos na cidade Recife fica a cargo do poder público municipal, sendo esta uma gestão compartilhada com algumas Secretarias. A Secretaria de Saneamento se envolve com os aspectos voltados ao Saneamento, no sentido de aumentar a área saneada do Recife, especialmente as áreas mais pobres da região; a Secretaria de Infraestrutura e Habitação, conta com a Autarquia de Urbanização do Recife (URB), que se tornou responsável pela elaboração e execução das obras que ocorrem nos riachos, assim como também trata da relocação das comunidades para os habitacionais que foram construídos.

Ligado à Secretaria de Infraestrutura e Serviços Urbanos, a Empresa de Manutenção e Limpeza Urbana (EMLURB) é responsável pelo sistema de drenagem da cidade. Lida com os aspectos voltados para a manutenção dos riachos, no sentido de limpeza e capinação. Também é de responsabilidade da Emlurb a criação do Plano Diretor de Drenagem da Cidade do Recife (PDDR), que está em vias de ser disponibilizado para a população.

O PDDR "busca não apenas traçar as diretrizes e ações básicas para o sistema de drenagem físico-material, mas também conjugar ações urbano-paisagísticas ao longo das linhas de drenagem da cidade, proporcionando melhor qualidade ambiental à cidade" (EMLURB, 2013). Fruto deste plano diretor está o documento intitulado "Proposta de intervenção urbanoambiental para as margens de rios e riachos da cidade do Recife", sendo este mais um eixo de trabalho vinculado a este órgão, que levou em consideração o que já foi realizado no âmbito do Projeto Capibaribe Melhor.

A Secretaria de Desenvolvimento Sustentável e Meio Ambiente trabalha com três grandes eixos de responsabilidades em relação aos riachos: o controle ambiental (fiscalização e licenciamento), conservação e renaturalização, conforme é destacado na fala a seguir:

O primeiro é o controle ambiental, que a Secretaria ela tem essa atribuição do controle ambiental de fazer a fiscalização e o licenciamento ambiental, e consequentemente acompanha aí o impacto do ser humano nesses riachos. Tem a brigada ambiental que faz essa fiscalização mais fina que vai desde o lançamento de dejetos até a ocupação urbana nessas áreas de riachos. [...] monitoramento, porque a gente ta fazendo isso via drone, o monitoramento dos cursos de água do Recife e a ocupação urbana para não avançar. A gente ta fazendo dos rios, mas também já está avançando para alguns riachos próximos aos rios (EPP04).

O segundo é a conservação dos riachos que ainda são possíveis de ser protegidos. Tem a Política de Unidades Protegidas e Conservação, dentro dessa política está inserido alguns riachos que ainda tem algum tipo de qualidade ambiental para fazer essa proteção (EPP04).

E o terceiro grande eixo é mais um princípio do que uma ação propriamente dita, que é o princípio da renaturalização. A gente tem essa intenção, já escrevemos alguns projetos, alguns projetos como o custo é muito alto, de retirada de moradias em áreas, a gente fez o primeiro projeto de renaturalização do rio Jiquiá, porque o rio Jiquiá ele nasce no Recife. A gente fez o projeto para a captação de recursos e estamos negociando com alguns organismos internacionais essa coisa da possibilidade da revitalização visando a renaturalização dos riachos urbanos (EPP04). 
Cada órgão é responsável pela busca de recursos para ser atribuídos em suas obras em relação aos riachos. Porém, dentre os órgãos, nota-se que os trabalhos que buscam a renaturalização dos mesmos estão mais relacionados com a Secretaria de Meio Ambiente, sendo o princípio da revitalização a melhor forma de trazer benefícios para a cidade do Recife.

Dentre os atores citados anteriormente, atribui-se a coordenação da gestão dos riachos urbanos à EMLURB, como relatam os trechos de falas a seguir:

Nesse aspecto ela estaria mais ligada a própria Empresa de Manutenção e Limpeza Urbana, que tem o papel justamente da manutenção, desses canais estarem limpos, estarem com o escoamento adequado, de não ter nenhuma obstrução. Nesse aspecto, a gestão é mais relacionada a Emlurb (EPPO3).

A gestão dos riachos urbanos é a Emlurb que coordena. A diretoria de manutenção urbana. A emlurb tem duas diretorias: a de manutenção urbana e limpeza urbana. Todas as duas atuam na manutenção dos riachos e gestão deles (EPP01).

Porém, ao se falar dos riachos com os moradores das comunidades, percebe-se que é a URB que entra em contato mais diretamente com eles. Nota-se portanto, uma gestão compartimentada na qual infelizmente percebe-se que os esforços não se somam, pois muitas vezes estão sobrepostos. É fundamental uma intersetorialidade e articulação entre todas as partes envolvidas com a gestão dos riachos urbanos na cidade do Recife.

Sendo assim, pode-se definir o seguinte arranjo institucional (Figura 2), na esfera municipal, acerca das ações relacionadas com a gestão dos riachos urbanos:

Figura 2 - Gestão municipal dos riachos urbanos em Recife.
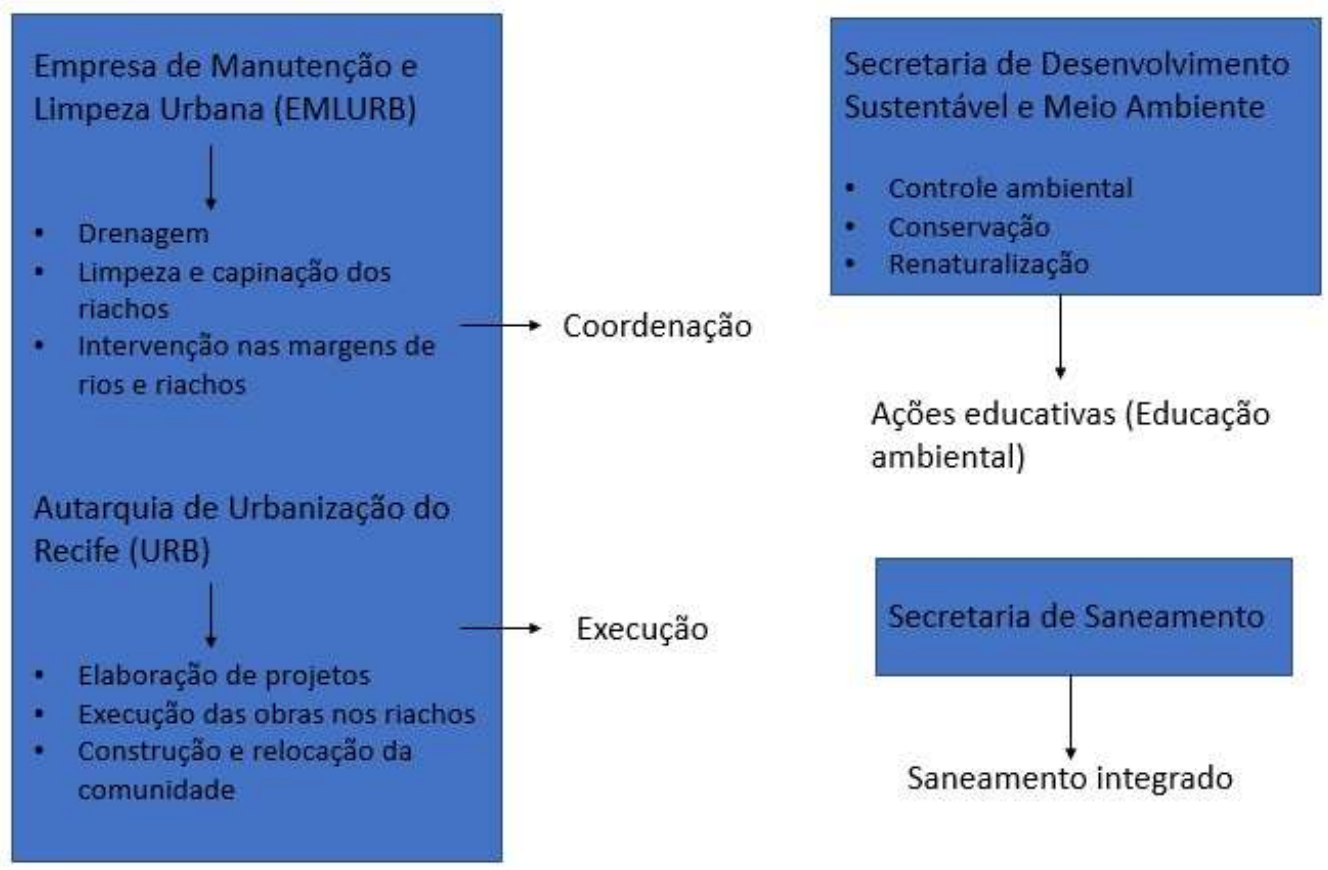

Fonte: Autores.

Como destacam Melgarejo-Moreno, López-Ortiz e Fernández-Aracil (2019), a correta gestão dos recursos hídricos tende a garantir as condições sanitárias da população da região e o sucesso de suas economias, a sustentabilidade de seus recursos naturais, políticas públicas e marcos institucionais aceitos pela sociedade.

Ao se analisar os órgãos e secretarias que tratam dos riachos urbanos na cidade do Recife, percebe-se um arranjo complexo, pouco definido e com baixa articulação entre os mesmos. 
Para uma gestão eficiente dos riachos é necessário canais de comunicação onde os órgãos e secretarias possam discorrer para que não haja sobreposição de trabalhos e que assim a responsabilidade possa ser compartilhada e interconectada para o bom funcionamento desta rede.

Foram encontrados indícios da utilização dos princípios da governança, sendo uns com mais efetividade, outros se encaminhando para um fortalecimento e alguns que não cumprem a função desejada. Cada princípio está discutido a seguir.

O princípio da transparência assegura que as decisões e informações se façam chegar aos atores e operadores das decisões tomadas. Marques (2007), traz que as informações precisam ser seguras, completas e transparentes, pois isso fará com que se haja confiança no processo decisório.

Percebe-se que na Prefeitura do Recife existem canais de comunicação com a sociedade civil em geral, principalmente em se tratando de uso da internet. Kunsch (2007) discutindo acerca da comunicação organizacional na era digital, ressaltou o poder que a comunicação digital tem na sociedade contemporânea. Contudo apontou para a necessidade de um monitoramento contínuo na rede para compreender as articulações do público e suas falas.

No que se refere a Prefeitura do Recife, percebe-se que esse canal de comunicação não é utilizado de maneira contínua, de maneira a manter um relacionamento com a população ou lideranças comunitárias, este é mais utilizado como forma de realização de reclamações ou na consulta por informações. Tirando este recurso, não há outro meio de se fazer comunicar sobre as decisões acerca dos riachos urbanos com a população, o que acaba por não ser possível para as pessoas analfabetas e excluídas digitalmente.

As atas do Conselho do Meio Ambiente (COMAM), conselho este ligado à Secretaria de Desenvolvimento Sustentável e Meio Ambiente, ficam disponíveis no site, sendo de fácil acesso pela população, além de informes que se dão através das redes sociais como Facebook e Instagram, sendo este hoje um dos métodos mais eficientes que tem a possibilidade do alcance da informação para um número superior de pessoas.

Como afirmam Souza Júnior et al. (2016), as decisões precisam ser baseadas em processos transparentes e bem informados, levando em considerações lições das situações que ocorrem em todo o mundo, pois assim, evita o uso de medidas que não são eficazes e desnecessárias.

[...] A gente que publica toda a ata, tenta fazer a ata o mais fiel possivel e publica todas as atas no site e no Diário Oficial da Prefeitura. Então isso já é a garantia mínima de que o debate, uma informação que foi gerada ali foi publicizada [...] Tem aí facebook, instagram, todos os meios de comunicação da Prefeitura têm divulgado (EPP04).

A gente nas reuniões tem sempre um espaço de informes e aí são trazidas essas notícias a respeito de outros seminários, simpósios, eventos relacionados com a temática [...] a gente fica sabendo a partir do conhecimento de cada conselheiro que trás um informe para a Câmara ou quando o Conselho mesmo a partir de outros membros noticia a Câmara pra que ela tome conhecimento e se manifeste sobre algum assunto correlacionado com aquela temática (EPP03).

Outro método de transparência se dá através de Ouvidorias do Estado, sendo locais onde pode se conseguir as informações relacionadas aos riachos urbanos. Apenas nota-se que canais de comunicação que permitam o contato com as pessoas são menos expressivos, não havendo ainda muitos locais para debates com os representantes das comunidades, como destacado a seguir:

Toda demanda que vem social, no caso da comunidade, vem pra gerência social que a gente tem aqui. Que é uma diretoria que foi transformada em gerência. Então eles funcionam até como uma ouvidoria, vamos dizer assim, e no caso tratam com a gente posteriormente. Aí chega a demanda da comunidade e eles encaminham pra gente pra ver a possibilidade de atender ou não (EPP02). 
Aqui na Emlurb tem dois setores, um de comunicação que isso é repassado para sociedade civil como um todo e para Prefeitura. E tem outro setor que uma assessoria ambiental. Quando existe alguma obra, alguma intervenção, ela faz essa ponte. Agora são coisas assim, não para projetos grandes, pode ser que isso venha a ser, a dragagem do rio Tejipió, o projeto para educação em si for objeto de execução, aí pode ser que comece essas discussões, serão necessárias com a comunidade. (EPP01).

Em Jaboatão dos Guararapes, cidade vizinha ao Recife, Silva (2018), ao entrevistar moradores de duas comunidades, chegou à conclusão que grande parcela da população descredibiliza as lutas socais que são realizadas, pois acreditam que os políticos não dão credibilidade as lutas que as comunidades que vivem em situação de vulnerabilidade enfrentam. O princípio da transparência da governança vem para que os canais de comunicação sejam eficientes e que a sociedade como um todo seja ouvida.

O princípio da descentralização deve garantir a inserção de outros atores nas tomadas de decisão e não apenas o Estado. Ainda é muito sutil a inserção de novos atores no processo decisório com relação aos riachos urbanos.

O processo de descentralização atua no aumento do poder democrático que exige, para seu exercício real, a participação efetiva e direta da população e da sociedade civil organizada. A vontade do povo se torna inválida quando a sociedade perde seu direito e dever de participação na gestão pública (Silvestre; Santos \& Paiva, 2018).

Os recortes de entrevistas a seguir mostram a relação de como o poder público enxerga essa descentralização na tomada de decisão.

[..] Então a gestão dos riachos se dá a partir desse conjunto de atores institucionais, as instâncias colegiadas de acompanhamento, como o próprio conselho da cidade, conselho de meio ambiente e também uma série de entidades da sociedade civil que tem um olhar que se volta pra... também estudar e apontar aspectos relacionados a gestão e aí de uma maneira geral a própria academia e outras instituições de interesse dentro dessa temática (EPP03).

E apesar de tantos órgãos gerindo, nunca foi assim, 100\% eficiente... nessa área (EPP01).

O poder de decisão fica a cargo da repartição pública e mais ainda, praticamente na mão de uma única secretaria. Quando infere-se a participação da sociedade civil, fica ainda mais distante o sentido de descentralização (EPP04 e EPP05). Corroborando com esse achado, Souza Junior et al. (2016) afirmam que o sistema de gestão das águas reforça um modelo burocrático com favoritismo ao conhecimento técnico, o que abarca em uma lacuna na participação da sociedade civil.

Não, não... a resposta mais simples é não. Porque não existe um mecanismo de gestão que envolva a sociedade civil pra construir até uma política de revitalização dos rios e da gestão (EPP04).

[...] Alguns estudantes, a sociedade civil no geral quando tem algum problema específico, com relação a inundação, a problema de invasão de área de preservação permanente [...] ele vem para o Estado e em geral não é uma preocupação com a qualidade do riacho, mas é uma preocupação com a qualidade de vida que a pessoa tem da valorização daquele espaço como um todo, não é se preocupando com o meio ambiente não (EPP05).

A participação pública se dá apenas no âmbito das audiências públicas, onde nota-se que são poucos os representantes das comunidades que delas participam (EEP01). Apenas quando as obras já estão no início das suas atividades, é que a população fica sabendo, não tendo o contato prévio com os moradores das comunidades. Se a obra vai ocasionar na relocação das casas, existe um espaço para geração destes debates, mas só para este fim, conforme destaca o fragmento de fala (EEP04). Souza Júnior et al. (2016) abordam que os conselhos acabam, muitas vezes, por se tornarem os braços políticos dos governos, porém estão distantes de representar os interesses de toda uma sociedade, como seria o objetivo.

Olhe, eu participei de várias audiências públicas e reuniões. Que eu tenho conhecimento, tem duas organizações assim, de bairros que participam, nesse sentido. [...] (EEP01). 
Aí sim, aí se houver qualquer tipo de obra, existe a participação pra diálogo para relocação, enfim..., mas é algo muito pontual do ponto de vista do uso do solo, não é da gestão do riacho [...] (EEP04).

O fragmento de fala a seguir, não condiz com a realidade ouvida dos moradores das comunidades. O órgão público afirma que a diretoria social faz um trabalho junto a eles antes do início de uma ação, remonta-se que isto só ocorre caso seja necessária a relocação dos moradores para outros locais (EEP02). Ferreira (2015) destaca que o atual modelo de gestão ainda se encontra hierarquizado e que isso limita a participação dos cidadãos no que se refere ao processo de tomada de decisões. E como apontam Silvestre, Santos e Paiva (2018) a participação da sociedade é saudável e suas decisões tendem a ser mais eficientes, pois apresentam soluções que são factíveis para os problemas das suas comunidades.

Existe uma diretoria social aqui, uma gerência social que trabalha com essa parte, que faz a parte técnica social das áreas onde vão ter intervenções da Prefeitura. Então quando estamos elaborando o projeto, a parte social todinha é levantada. Então acredito que existe esse contato junto com a comunidade com os técnicos sociais que eles vão na área toda e levantam todos os dados sociais antes da prefeitura elaborar um projeto. A gerência social (EEP02).

[...] Prefeitura aqui não vem dar satisfação até agora em nada, só vem só em tempo de eleição pra vim atrás de voto, mas pra prometer, fazer serviço não (ESCO4).

[...] A gente não pode nem opinar porque a gente não tem opções (ESC04).

[... ]espaço pra opinar pra Prefeitura, pra melhoria não (ESCO2).

Luz, Mazzarino e Turatti (2021) afirmam o quanto é essencial a participação descentralizada e corresponsável. A Figura 3 discorre sobre a frequência de palavras sobre a descentralização nas entrevistas com os stakeholders na gestão dos riachos urbanos.

Figura 3 - Frequência de palavras sobre descentralização nas entrevistas com os stakeholders dos riachos urbanos.

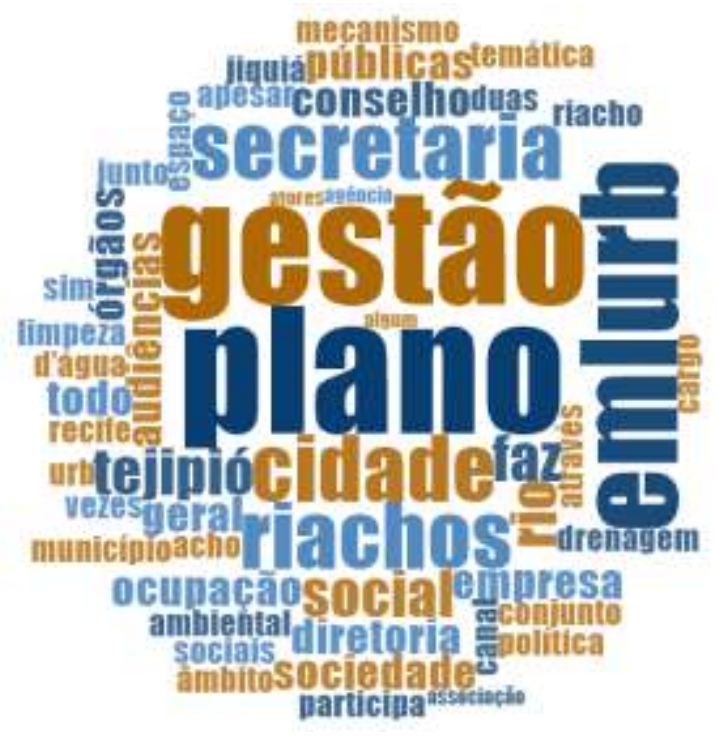

Fonte: Elaboração com auxílio do Software NVivo (2018).

Percebe-se que que as palavras "participa", "sociedade”, “conjunto", “junto", "mecanismo" que remetem a entrada de outros atores nas tomadas de decisão se faz muito discreta ainda no cenário dos debates acerca dos riachos urbanos e da gestão do território das comunidades em si, revelando que ainda está na mão do poder público esse poder decisório.

O princípio da flexibilidade atua fazendo com que o Estado deixe de ser o decretador e passe a agir como negociador. Na Prefeitura da cidade do Recife existem alguns locais de debates, onde a população poderia através de seus 
representantes tomarem assentos para participar das discussões, como as audiências públicas, as câmaras técnicas e o Conselho de Meio Ambiente. Contudo, apesar de existirem estes espaços, o princípio da flexibilidade ainda não é um instrumento eficaz, o estado continua sendo o decretador das opiniões e das ações, sendo sutilmente aberto para as opiniões.

Nota-se também que estes espaços abarcam mais a comunidade técnico e científica sobre o assunto, como o Grupo de Recursos Hídricos da Universidade Federal de Pernambuco e da Empresa privada ABF (empresa que concebeu os estudos sobre o Plano Diretor de Drenagem da Cidade do Recife). Em relação a sociedade civil em geral, principalmente os líderes comunitários, não há tanta abertura para os debates, como pode ser concebido com os trechos de entrevistas a seguir:

Nos projetos, não. Realmente, nos projetos a comunidade não dá sugestão (EPP01).

Não. É tanto que tem uma discussão na audiência pública do plano diretor, foi pouca gente. Representantes da sociedade de uma maneira geral e foi pouca gente na audiência, ne (EPP01).

Apesar da URB informar que a empresa possui um local onde a comunidade pode ir debater (fragmento de fala a seguir), ao conversar com os líderes comunitários não se percebe que este local é de fácil acesso e que eles conseguem o que precisam para suas moradias ou para a comunidade. Acaba se tornando um espaço onde o poder público mais uma vez vai passar a informação que já foi consolidada internamente, sem estes representantes sociais.

Tem. Aqui tem reuniões aqui. Quando a comunidade... aqui semanalmente o auditório é cedido para a comunidade para discutir com a diretoria de social e habitação. Então essa diretoria ela cuida toda dessa parte ai, apresenta como vai ser a obra, os inconvenientes que ela vai causar, mas também os benefícios que ela vai ter lá na frente (EPP02).

“Em alguns casos é necessário antes mudar culturas, comportamentos e atitudes, compreendendo que o sentido real da governança é criar um ambiente no qual seja possível aos vários atores discutir problemas e buscar, em conjunto, soluções negociadas e efetivas" (Denny, Granziera \& Gonçalves, 2020, p.240).

O princípio da subsidiariedade deve atuar no sentido do Estado passar ao máximo as responsabilidades que lhe competem, para outros órgãos, secretarias, comunidade. O Estado consegue transferir responsabilidades à medida que contrata empresas, grupos de pesquisas, universidades para complementar os estudos sobre os riachos urbanos, assim como também deixa a cargo dos Conselhos as discussões sobre o tema.

A empresa privada $\mathrm{ABF}$ foi contratada para o desenvolvimento de inúmeros estudos que contemplassem a criação do Plano Diretor de Drenagem do Recife, principalmente direcionado aos aspectos da macro e microdrenagem.

O Grupo de Recursos hídricos há 11 anos trabalha com a temática dos riachos urbanos na cidade do Recife, mas ainda possuem dificuldades na hora de encontrar um órgão ou secretaria para que possam contribuir. Nota-se que as responsabilidades são sempre repassadas para um outro local, não achando um meio formal de participarem das discussões e terem essa responsabilidade adquirida, o que contraria o princípio da subsidiariedade, como destacam Favarão e Costa (2018), que atua dando uma maior autonomia aos atores locais e as estruturas de participação da sociedade civil.

Eu diria assim que formalmente não, mas como a gente conhece várias pessoas dos órgãos a gente termina dando algum pitaco, dando palpite. Formal não, até porque Recife não formaliza que existem riachos, tá?! Se você for na Prefeitura eles vão dizer que a cidade não tem riachos, que o que tem são canais de drenagem (EU01).

Muito da concepção dos projetos para os riachos urbanos fica a cargo do poder público e de empresas terceirizadas em distintas secretarias, portanto com olhares e funções também distintos. Quando o Estado repassa as responsabilidades, pode atuar no sentido do gerenciamento e na articulação dos diversos órgãos e secretarias na busca de propostas que se integrem e que realmente tragam benefícios. 
Os dois. Hoje no quadro da Urb acho que está sem projetista, mas são empresas terceirizadas. Tem várias. Tem projetos de várias empresas (EPP02).

A ideia dos projetos de revitalização e renaturalização partem da Secretaria de Meio Ambiente (EPP04).

É fundamental que as secretarias possam se interligar para evitar as superposições de trabalhos e assim dialogarem em uma perspectiva mais ampla do problema.

O princípio da participação/empoderamento tende a garantir artifícios que facilitem o acesso a diferentes atores para contribuir no processo decisório. Apesar de terem sido listados canais de comunicação entre o poder público e a sociedade, ainda são incipientes a participação e o empoderamento dos representantes comunitários nas discussões. Sabe-se que são atores que vão conviver com as obras que ocorrem em suas comunidades, mas que só sabem do acontecimento delas na hora em que iniciam a execução dos planos.

O Fórum do PREZEIS pode ser evidenciado como um mecanismo onde nota-se esta participação, ele foi utilizado como local de debates no Capibaribe Melhor, para algumas pessoas. Baldiwin et al. (2018) destacam que a ação coletiva preconiza-se no fato de que os atores tenham incentivos para cooperar, que haja confiança mútua e que sintam legitimidade no processo.

[...] mas a gente tem uma coisa que é uma conquista histórica do Recife que é o Fórum do PREZEIS. O PREZEIS congrega os representantes das diversas zonas especiais de interesses sociais da cidade. [...] (EPP03).

Compreender as implicações das percepções e expectativas dos moradores da cidade para o planejamento do espaço em que vivem, torna-se uma questão fundamental para estimar o endosso público, orquestrar a participação pública, apoiar o trabalho educacional e assegurar a coerência na estratégia de governança (Zingraff-Hamed et al., 2017).

A participação pode ser mobilizada por meio da educação ambiental junto aos moradores, e é essencial para busca de um meio ambiente equilibrado. Conhecendo as funções ambientais, hidráulicas e hidrológicas do riacho, cria-se o sentido de empoderamento e cuidado com o recurso ambiental, conforme destacou a pesquisa de Gouveia e Selva (2018) nos riachos urbanos do Recife.

O envolvimento da sociedade civil faz com que se equilibre os interesses privados e o setor público, pois através de mecanismos compartilham o conhecimento que pode ajudar a evitar retrocessos que estão associados as mudanças políticas (Sousa Júnior et al., 2016). Esse envolvimento se dá pelo empoderamento dos atores sociais das comunidades nos níveis individual e coletivo, onde Kleba e Wendausen (2009) descrevem como a possibilidade de emancipação dos indivíduos, respeito e apoio dos membros.

O princípio do pertencimento demonstra que os atores precisam assumir as decisões como suas. A comunidade técnica e científica frequentemente é buscada para os debates, mas o poder público informa que ainda é carente a busca dos líderes comunitários para cuidarem do riacho que vivem em seu entorno, como pode ser observado nos seguintes fragmentos de fala:

Ah, sim. Durante o plano, a gente fez isso, né? Chamou a universidade, chamou atores da sociedade civil, teve uma audiência pública, onde essas coisas foram discutidas por esses atores, entendeu? Principalmente a comunidade técnica mais diretamente ligada ao assunto, né (EEP01).

A gente não tem informações sobre isso. A gente nem toma ciência do que está sendo discutido na Emlurb, é algo bem separado (EPP05).

Eu acredito que a prefeitura em si, ela não tem levado muito a sério essas tomadas de decisões, essas sugestões da comunidade (EPPO1). 
Permanecer por muito tempo residindo nestes locais e anseiam para serem relocadas ou indenizadas para habitarem outros espaços urbanos. Vivem na incerteza e muitas vezes não sabem como buscar o órgão público para debates e conhecimento. Zingraff-Hamed et al. (2017) afirmam que para reverter as mudanças morfológicas históricas e restaurar as funções sociais e ecológicas é necessária a cooperação entre as partes interessadas que trabalham em diferentes agências e governo.

O diálogo com as comunidades que vivem as margens do recurso natural se faz imprescindível para subsidiar ações de preservação e conservação que respeitem a percepção dos moradores locais, revelando e fortificando seus saberes (Dictoro, 2021).

O princípio da responsabilização tem por base prover informações, prestar esclarecimentos e garantir o cumprimento das sanções. Este é um princípio que é possível de se observar na gestão dos riachos na cidade do Recife.

Há alguns anos, existia um mecanismo de controle social dos montantes que seriam gastos em obras públicas, chamado de orçamento participativo. Desde 2004, o Portal da transparência foi lançado sendo uma instância de controle social dos recursos, onde todos os valores destinados às secretarias se encontram disponíveis para consulta pública. Não é uma ferramenta fácil de ser utilizada, mas nela podem ser encontradas as informações necessárias para um controle social dos montantes gastos com as obras.

Os fragmentos de fala a seguir demonstram a visão de alguns dos stakeholders sobre os mecanismos de controle social dos recursos:

Olhe, eu acredito que não. Eu não saberia responder a essa pergunta. Porque na gestão anterior, existia aquele órgão de orçamento participativo, aquele programa que todas as comunidades indicavam de ser aplicados os recursos da prefeitura. É que essa gestão eu não tenho conhecimento, não sei lhe informar se tem essa participação (EPPO1).

Eles participam mais em termos de manutenção, mais aquele negócio de atendimento a demanda, quer dizer, isso aí são coisas muito pontuais. A pessoa liga reclamando que está alagado, então a Emlurb vai lá... não tem uma participação coletiva, mas participação pontuais das pessoas (EPPO1).

. [...] Os investimentos do Poder Público eles são hoje todos disponibilizados no Portal da transparência, a questão dos contratos executados a partir das diversas secretarias e aí qualquer cidadão que entrar na internet, no Portal e vê essa prestação de contas (EPP03).

A busca por orçamentos para realização de projetos que visem a melhoria do sistema de macrodrenagem na cidade do Recife, se dá separadamente por cada secretaria de governo. Estes buscam recursos do orçamento municipal, além da captação de recursos externos. A CPRH possui o mecanismo do ICMS socioambiental que repassa montantes para os municípios, mas esse valor não necessariamente se restringe a obras ambientais, eles também servem para suprir a carência de saúde, educação ou de outra demanda.

O princípio da segurança vem a garantir que as pessoas estejam livres de qualquer tipo de ameaça. Infelizmente, na cidade do Recife, este não é um princípio que tem êxito, pois alguns representantes de órgãos públicos afirmam que não se sentiram seguros em comunidades residentes no entorno dos riachos. Vê-se que isso se dá com órgãos que precisam desapropriar moradores ou fazer alguma intervenção que vá alterar a rotina dos moradores, como pode ser visto nos fragmentos de fala a seguir:

Sempre a comunidade, infelizmente, tenta se aproveitar da presença da prefeitura. De que forma? Tentando ocupar o espaço em que um canal vai passar, pra poder receber qualquer tipo de reembolso por desapropriação, tudo (EPPO2). 
[...] Ano passado, em novembro, mataram o vigia da gente com seis tiros, então eles chegam lá e querem ser o dono da área, né?! (EPP02).

Esse é um princípio que se notam falhas em sua estrutura, seja pela ineficiência dos canais de comunicação formais ou pela comunidade que não se sente ouvida em seus anseios e acreditam que precisam defender o seu território de qualquer forma. Por isso que o diálogo prévio com a comunidade se faz uma ferramenta chave para êxito. Quando a população é inserida desde o início do planejamento das mudanças necessárias, elas podem opinar e garantir que suas necessidades sejam ouvidas, fazendo com que possam cuidar melhor do ambiente em que vivem e não tendo tanto embate com os órgãos públicos.

De acordo com Luz, Mazzarino e Turatti (2021, p.41) “os conflitos são outro elemento central para os teóricos da governança, especialmente, a hídrica. Há quem compare a gestão da água à própria gestão de conflitos, tendo em vista a dimensão que eles assumem no manejo deste recurso, causados, principalmente, pela concorrência entre os diversos usos".

Em se tratando de um órgão estadual, como a CPRH, que fiscaliza e concede licenças, não é relatado ameaças, como pode ser visto no fragmento de fala seguir:

Na verdade, assim, não é ameaça. Muitas pessoas tentam subornar, mas ameaçar é mais difícil assim. Nessa área, a gente tem ameaça quando por exemplo, extração de madeira, tráfico de animais, isso em geral é ameaça, ameaça de morte, aquela coisa. Mas quando é ocupação urbana, geralmente é assim: finge que não viu, eu te dou tanto e você aprova isso aqui, então é mais no sentido de suborno, de ameaça não (EPP05).

O gráfico de frequência de palavras mostra como as palavras "pessoas", "comunidade" e "problemas" estão ligadas, direcionando para o entendimento de que esta relação ainda é conflituosa (Figura 4).

Figura 4 - Nuvem de palavras- princípio da segurança.

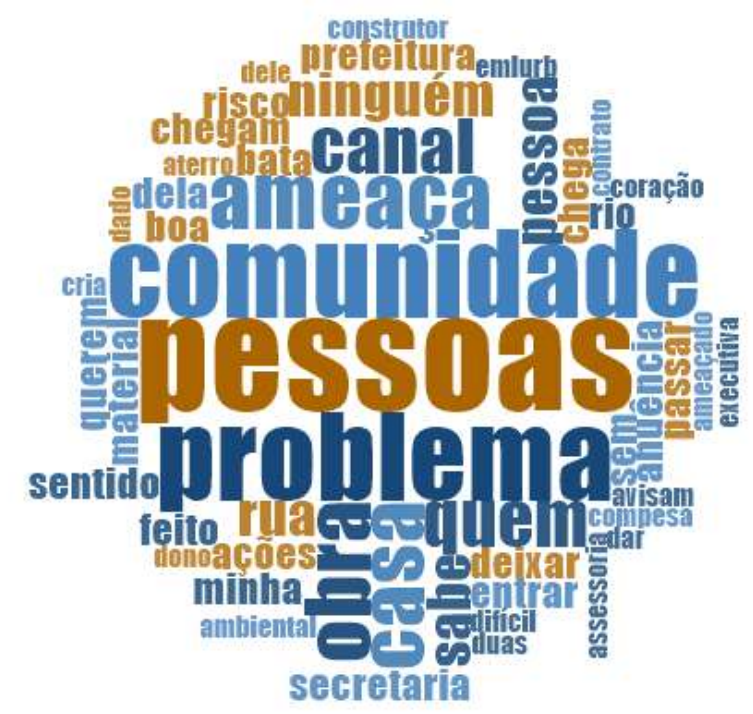

Fonte: Elaboração com auxílio do Software NVivo (2018).

Estas três palavras foram muito relacionadas nas entrevistas, demonstrando que esse não é um princípio eficaz em relação aos riachos na cidade do Recife e que necessita de mudanças para que todos os atores possam se sentir seguros.

\section{Considerações Finais}

A responsabilidade pela gestão dos riachos urbanos não pode ser individualizada, mas sim compartilhada, e foi notado que a comunidade não se sente parte integrante no processo de tomada de decisão das obras que vão ocorrer em suas 
comunidades. Embora a revitalização dos riachos na cidade do Recife ocorra de maneira compartimentada e com sobreposição de funções, há indícios de utilização dos princípios da boa governança em relação aos riachos urbanos;

Os princípios da transparência, subsidiariedade, participação, pertencimento e responsabilização podem ser visualizados de maneira ainda muito tímida, principalmente quando envolve a participação da sociedade civil. A Universidade e empresas privadas são mais acolhidas nesse processo. Os princípios da descentralização, flexibilidade e segurança não são praticados na gestão dos riachos urbanos;

Infelizmente a cultura de representação e de participação ainda não está bem formatada no Brasil. Uma estratégia de solução seria a diversificação de canais de comunicação e o fortalecimento da relação governo x comunidade, dando maior credibilidade as ações desenvolvidas. A governança, no seu sentido normativo, precisa ser entendida como a inclusão de novos atores no processo decisório, para que assim todos possam ajudar no enfrentamento dos problemas localizados nas cidades, principalmente para salvaguardar um bem tão precioso, quanto os riachos.

Para trabalhos futuros é importante que se mostra mostrar ao poder público a relevância de ter canais de participação efetivos com a comunidade para que as obras possam fazer sentido para moradores e assim a revitalização/renaturalização dos corpos hídricos ocorra de forma efetiva, aliando conservação e preservação.

\section{Referências}

Baldwin, E., Mccord, P., Dell'angelo, J. \& Evans, T. (2018) Collective action in a polycentric water governance system. Environmental Policy and Governance. 28 (4), 212-22. https://doi.org/10.1002/eet.1810

Bonini, A. (2008). Industrialização, urbanização e trabalho nas décadas de 1960 e 1970: a construção do Paraná moderno. Anais... Seminário do Trabalho. Marília, p. $01-16$

Bursztyn, M. A., \& Bursztyn, M. (2012). Fundamentos de política e gestão ambiental: caminhos para a sustentabilidade. Ed. Garamond, 612p.

Carvalho, L. E. P. (2012). O domínio das águas, o Recife se faz no tempo. Mnemisone. 3(1).

Denny, D. M. T., Granziera, M. L. M., \& Gonçalves, A. F. (2020). Comitês de bacia hidrográfica: governança e efetividade na gestão de recursos hídricos. Revista gest. sust. ambient. 9(4), 227-47.

Dictoro, V. P. (2021). Água e seres humanos: relações simbólicas e culturais visando à Conservação. Revista Guia: Integrando seres e saberes. 2(1), 45-46.

Emlurb. (2016). Cadastro de Canais: álbum do Sistema de macrodrenagem da cidade do Recife- R01, EMLURB.

Espada, A. L. V., \& Sobrinho, M. V. (2015). Manejo comunitário e governança ambiental para o desenvolvimento local: análise de uma experiência de uso sustentável de floresta na Amazônia. Administração Pública e Gestão Social, 7(4), 169-177.

Favarão, C. B., \& Costa, M. A. (2018). Governança e políticas nacionais urbanas: capacidade e desenvolvimento institucional. In: Costa, M. A., Magalhães, M. T. Q., \& Favarão, C. B. A nova agenda urbana e o Brasil: insumos para sua construção e desafios a sua implementação / organizadores:- Brasília: Ipea.

Ferreira, I. (2015). Governação, participação e desenvolvimento local. Sociologia, Porto. 30, 97-117.

Gouveia, R. L., \& Selva, V. S. F. (2018). Riachos urbanos do Recife: educação ambiental como ferramenta para a revitalização. Educação ambiental em ação. (65), Ano XVII.

Guedes, R. P., Araújo, M. P. S., \& Andrade, A. P. G. (2021). Necessidade do gerenciamento dos recursos hídricos em grandes cidades como Recife. Architecton - Revista de Arquitetura e Urbanismo. 6(09), 1-11.

Kleba, M. E., \& Wendausen, A. (2009). Empoderamento: processo de fortalecimento dos sujeitos nos espaços de participação social e democratização política. Saude soc., 18(4), 733-43.

Kunsch, M. M. K. (2007). Comunicação organizacional na era digital: contextos, percursos e possibilidades. Signo y Pensamiento, XXVI (51) 38-51.

Lage, M. C. (2011). Utilização do software NVivo em pesquisa qualitativa: uma experiência em EaD. ETD - Educação Temática. Digital., $12,198-226$.

Luz, J. P., Mazzarino, J. M., \& Turatti, L. Uma perspectiva tridimensional para a compreensão da governança no âmbito dos comitês de bacias hidrográfica. In: Rempel, C., Turatti, L., \& Dalmoro, M. (2021). Desafios da sustentabilidade. Ed. Univates

Marconi, M. A., \& Lakatos, E. M. (2007). Fundamentos de metodologia científica. (6a ed.), Atlas.

Marques, M. C. C. (2007). Aplicação dos princípios da governança corporativa ao sector público. Revista de Administração Contemporânea. 11(2), 38-51, Curitiba. https://doi.org/10.1590/S1415-65552007000200002 
Research, Society and Development, v. 10, n. 12, e146101220197, 2021

(CC BY 4.0) | ISSN 2525-3409 | DOI: http://dx.doi.org/10.33448/rsd-v10i12.20197

Matarazzo, G., Quintão, F., \& Serva, M. (2021). Vigiar ou Educar: A Governança Ambiental como Experiência. Administração Pública e Gestão Social. $13(2), 1-16$

Melgarejo-Moreno, J., López-Ortiz, M., \& Fernández-Aracil, P. (2019). Water distribution management in South-East Spain: A guaranteed system in a context of scarce resources. Science of the Total Environment. 648, 1384-1393

Oliveira, S. S. R., \& Gomes, G. (2021). Políticas habitacionais e modernização autoritária nas ditaduras do Brasil e da Argentina (1964-1973). Esboços, 28(47), 38-58.

Pereira A. S. et al. (2018). Metodologia da pesquisa científica. UFSM.

Preuss, S. L. C. (2013). A revitalização de riachos urbanos na busca de cidades sustentáveis: o caso do riacho Parnamirim em Recife- PE. Dissertação (Mestrado em Engenharia Civil, Tecnologia Ambiental e Recursos Hídricos). Universidade Federal de Pernambuco, Recife.

Silva, D. S. (2018). A segregação socioespacial e o acesso à água: um estudo em duas comunidades urbanas em Jaboatão dos Guararapes - PE. 123f. Dissertação (Mestrado em Consumo, Cotidiano e Desenvolvimento Social). Universidade Federal Rural de Pernambuco, Recife.

Silvestre, G. C., Santos, N. M. B. F., \& Paiva, B. G. M. (2018). Novas formas de participação na gestão pública: um sistema alternativo para garantir a participação efetiva da comunidade local. Revista da Universidade Vale do Rio Verde. 16(1). https://doi.org/10.5892/ruvrd.v16i1.4910

Souza Junior, W., Baldwin, C., Camkin, J., Fidelman, P., Silva, O., Neto, S., \& Smith, T. F. (2016). Water: Drought, crisis and governance in Australia and Brazil. Water (Switzerland). 8 (11), 31, Article number 493

Vargas, H. L. (2008). Ocupação irregular de APP urbana: um estudo da percepção social acerca do conflito de interesses que se estabelece na lagoa do prato raso, em Feira de Santana, Bahia. Sitientibus, Feira de Santana. 39, 7-36.

Zingraff-HAmed, A., Greulich, S., Wantzen, K. M., \& Pauleit, S. (2017). Societal drivers of european water governance: A comparison of Urban river restoration practices in france and Germany. Water (Switzerland). 9(3), Article number 206. 1-19. https://doi.org/10.3390/w9030206 